\title{
Cultural practices among patients visiting ARV OPD of Government Medical College, Latur
}

\author{
A S Nagaonkar ${ }^{1}$, Quazi Sana ${ }^{2 *}$ \\ 1,2Department of Community Medicine, Government Medical College, Latur, Maharashtra, INDIA. \\ Email: sana106quazi@gmail.com
}

\section{$\underline{\text { Abstract }}$}

\begin{abstract}
Background: Rabies is a fatal disease. Although a number of carnivorous and bat species serve as natural reservoir, dog is a source of $97 \%$ of human infection. Globally about 61000 death occur annually due to rabies out of which 16450 (27 $\%)$ occur in India. In India wide variety of cultural practices are being practiced by the people following animal bite which determine their treatment seeking behaviour and prognosis of the wound. Objective: 1) To study epidemiological profile of animal bite cases visiting ARV OPD of Government Medical College, Latur. 2) To study cultural practices practiced by the same animal bite cases before visiting to ARV OPD. 3) To give recommendations based on the findings. Methodology: A cross-sectional study was conducted in ARV OPD of Government Medical College, Latur. Study was conducted for a period of 1 month from 1st of Sep 2019 to 30 of Sep 2019. All the new animal bite cases that is 184 cases visiting to ARV OPD were enrolled in the study. Data was collected using predesigned and pre-tested questionnaire. Data was entered in MS- Excel and analyzed. Results: Majority of the animal bite cases were hindu (161) by religion and were from joint family (113). Out of total animal bite cases $48.40 \%$ of cases were educated above higher secondary. 151 cases of 184 were of Dog bite, 32 were of cat bite and 1 was of pig bite case, Out of 188 animal bite cases, 88 ( $46.80 \%$ ) were of Cat III, 98 ( $52.12 \%$ ) were of Cat II and 2 ( $1.06 \%$ ) were of Cat I. Various cultural practices were practiced by 118 animal bite cases out of total 188 animal bite cases before visiting to ARV OPD. A significant difference was found between education level of animal bite cases and pre-treatment practices. Conclusion: The study reveals more than half of animal bite cases were practicing various cultural pre-treatment practices which are of no use and sometimes harmful. Awareness is needed through proper health education measures for appropriate health seeking behaviour and management of animal bite.
\end{abstract}

Key Words: Animal bite, Cultural Practices.

*Address for Correspondence:

Dr. Quazi Sana, Department of Community Medicine, Government Medical College, Latur, Maharashtra, INDIA.

Email: $\underline{\text { sana106quazi@gmail.com }}$

Received Date: 06/12/2019 Revised Date: 10/01/2020 Accepted Date: 03/02/2020

DOI: https://doi.org/10.26611/10111331

\begin{tabular}{|l|l|}
\hline \multicolumn{2}{|c|}{ Access this article online } \\
\hline Quick Response Code: & Website: \\
\hline & www.medpulse.in \\
& \\
\hline
\end{tabular}

\section{INTRODUCTION}

Rabies is a fatal disease. 10th biggest cause of death due to infectious disease is rabies ${ }^{1}$. The causative agent belongs to genus Lyssavirus of the family Rhabdoviridae. ${ }^{2}$ Rabies is present in all continents except Antartica and more than $95 \%$ of death are reported from
Asia and Africa. ${ }^{3}$ Globally 61000 death occur annually due to rabies, of which 16,450 ( $27 \%$ ) are reported from India. ${ }^{4}$ In India rabies is reported from all states except Lakshadweep and Andaman Nicobar Islands. ${ }^{5}$ The incidence of animal bite in India is 17.4 per 1000 population and about 1 person is bitten every 2 sec.6 About 2.74 rabies cases / 10,000 population annually is the fair estimate of rabies burden in India. 1 Of all the cases about $97 \%$ of rabies are due to bite from rabid dogs followed by bite of other animals such as cat, cow, monkey, horse, pigs ,camels which can be reduced if adequate animal vaccination and control, education of risk individuals, appropriate medical care is ensured..$^{7-8} \mathrm{In}$ India rabies is found to affect mainly poor and vulnerable population from low socio-economic status and mainly children in the age-group of 5-15 year in remote rural communities, but only a few parents sought medical advice that too with delay.9-10 Each year approximately 
1.1 to 1.5 million people are receiving post exposure prophylactic treatment. ${ }^{11}$ In spite of receiving post exposure prophylaxis there are reported treatment failures resulting in human rabies. Various reason responsible for this are - a) Delay in starting treatment due to late reporting of patients b) No proper wound wash c) Suturing of animal bite wounds without local infiltration of RIG d) Application of irritants to bite wounds. ${ }^{12}$ There are many myth and false belief associated with wound management like application of turmeric, burning of wound etc among people which are not useful and scientific and determine post exposure treatment seeking behavior of animal bite victims. Among general community there is a need to create awareness regarding epidemiology and management of animal bites. The study was done with an objective of determining epidemiological profile of animal bite cases and various cultural practices practiced by the same before visiting ARV OPD.

\section{MATERIAL AND METHODS}

The present cross sectional study was conducted at ARV OPD of Govt. Medical College, Latur. The study was conducted for a period of 1 month from 1st September
2019 to 30 September 2019 with an objective to determine variety of cultural practices practiced by the patients before visiting ARV OPD .All the new animal bite patients visiting to ARV OPD were enrolled in the study. Total 184 animal bite cases participated in the study. Data was collected using a predesigned and pretested questionnaire by interviewing them in local language. The questionnaire included socio-demographic data and information in relation to time interval between bite and attending ARV clinic, type of animal bite with category, and various cultural practices practiced by the patient before visiting ARV OPD. In case if animal bite case was of age 12 or below the information was obtained from the person accompanying the animal bite case. At the end of interview all the animal bite cases were given knowledge regarding hazard of various cultural practices and importance of complete post-exposure prophylaxis. The animal bite cases who refused to give information were excluded from the study.

\section{Statistical Analysis:}

Data was entered in Microsoft Excel and Analyzed. Frequencies and percentage were calculated. Chi square was used.

\section{RESULTS}

Out of total 188 animal bite cases 129 were male and 59 were female. Less than 12 year of age were 74 and greater than 12 were 114 animal bite cases. From urban area there were 121 cases and 66 from rural area. Majority of the animal bite cases were hindu (161) by religion and were from joint family (113). Out of total animal bite cases $48.40 \%$ of cases were educated above higher secondary. Out of 188 animal bite cases, 65 cases were belonging to SEC II, 58 to III, 62 to IV and 2 to V.( Table No. 1)

\begin{tabular}{cccc}
\multicolumn{4}{c}{ Table 1: Sociodemographic Profile of Animal Bite cases } \\
\hline Sr. No. & Sociodemographic Factors & Frequency (N=188) & Percentage \\
1. & Age & & \\
\hline & $<12$ & 74 & $39.36 \%$ \\
2 & $>12$ & 114 & $60.63 \%$ \\
& Sex & 129 & $68.61 \%$ \\
3 & Male & 59 & $31.33 \%$ \\
& Female & & \\
& Address & 122 & $64.89 \%$ \\
Urban & 66 & $33.51 \%$ \\
& Rural & & \\
& Religion & 161 & $85.63 \%$ \\
& Hindu & 25 & $13.29 \%$ \\
& Muslim & 1 & $0.53 \%$ \\
& Buddhist & 1 & $0.53 \%$ \\
& Others & & \\
& Education & 3 & $1.59 \%$ \\
& Illiterate & 0 & $0 \%$ \\
& Primary & 28 & $14.89 \%$ \\
& Secondary & 66 & $35.01 \%$ \\
& Higher Secondary & 32 & $17.02 \%$ \\
Graduate & 59 & $31.38 \%$ \\
\hline
\end{tabular}




\begin{tabular}{|c|c|c|c|}
\hline \multirow[t]{7}{*}{3.} & Occupation & & \\
\hline & Housewife & 27 & $14.36 \%$ \\
\hline & Agricultural Labourer & 23 & $12.23 \%$ \\
\hline & Non-agricultural labourer & 59 & $31.38 \%$ \\
\hline & Service & 36 & $19.14 \%$ \\
\hline & Business & 25 & $13.29 \%$ \\
\hline & Student & 18 & $9.57 \%$ \\
\hline \multirow[t]{6}{*}{4.} & Socioeconomic status & & \\
\hline & Class I & 0 & 0 \\
\hline & Class II & 65 & $34.57 \%$ \\
\hline & Class III & 58 & $30.85 \%$ \\
\hline & Class IV & 62 & $32.97 \%$ \\
\hline & Class V & 3 & $1.59 \%$ \\
\hline \multirow[t]{4}{*}{5.} & Type of family & & \\
\hline & Nuclear & 21 & $11.17 \%$ \\
\hline & Joint & 113 & $60.10 \%$ \\
\hline & Three generation & 54 & $28.72 \%$ \\
\hline
\end{tabular}

Of total animal bite cases, $48.93 \%$ cases has approached to ARV OPD within $24 \mathrm{hr}$, in the range of 1-2 days were $39.36 \%$, in a range of $2-4$ days were $10.63 \%$ and greater than 4 days were $1.06 \%$. ( Table No 2 )

Table 2: Time interval between bite and attending ARV Clinic

\begin{tabular}{ccc}
\hline Time interval & Frequency & Percentage \\
\hline Within $24 \mathrm{hr}$ & 92 & $48.93 \%$ \\
$1-2$ days & 74 & $39.36 \%$ \\
$2-4$ days & 20 & $10.63 \%$ \\
$>4$ days & 2 & $1.06 \%$ \\
\hline Total & 188 & 100 \\
\hline
\end{tabular}

151 cases of 188 were of Dog bite, 32 were of cat bite, 4 were of monkey bite and 1 was of pig bite case.(Table-3)

Table 3: Distribution of cases as per type of animal bite

\begin{tabular}{ccc}
\hline Animal & Frequency & Percentage \\
\hline Dog & 151 & $80.31 \%$ \\
Cat & 32 & $17.02 \%$ \\
Monkey & 4 & $2.12 \%$ \\
Pig & 1 & $0.53 \%$ \\
Other & 0 & $0 \%$ \\
\hline Total & 188 & 100 \\
\hline
\end{tabular}

Out of 188 animal bite cases, 88 (46.80\%) were of Cat III, 98 (52.12\%) were of Cat II and 2 (1.06\%) were of Cat I. (Fig. 1)

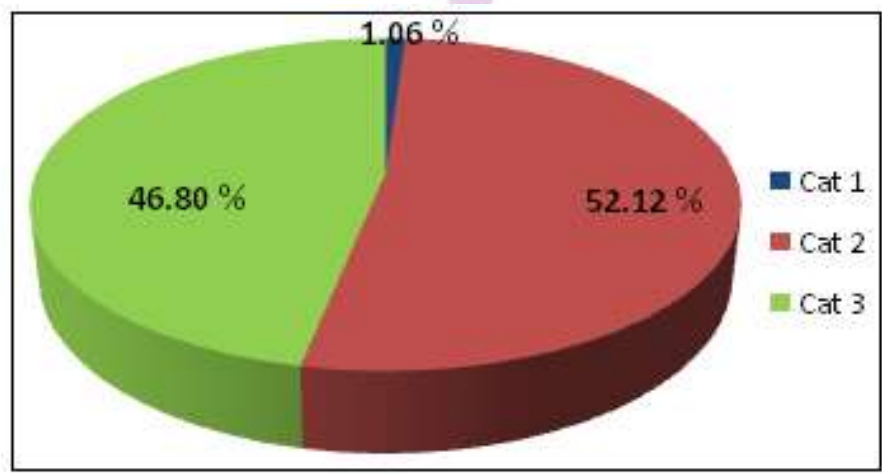

Figure 1: Distribution of cases as per type of category

Table 4: Distribution of animal bite cases according to pre-treatment practices

\begin{tabular}{ccc}
\hline & Frequency & Percentage \\
\hline Various Cultural Practices & 118 & $62.76 \%$ \\
No Pre-treatment practices & 70 & $37.23 \%$ \\
\hline Total & 188 & $100 \%$ \\
\hline
\end{tabular}


Table 5: Cultural Practices related to animal bite cases

\begin{tabular}{ccc}
\hline Cultural Practices & $\begin{array}{c}\text { Number } \\
(\mathrm{N}-118)\end{array}$ & $\begin{array}{c}\text { Percentage } \\
\text { Lime }\end{array}$ \\
\hline Burning & 40 & $9 \%$ \\
Burning, Lime,Veeda & 46 & $21.3 \%$ \\
Burning,Lime & 10 & $5.3 \%$ \\
Burning,Veeda & 4 & $2.1 \%$ \\
Lime,veeda & 1 & $5 \%$
\end{tabular}

Various cultural practices were practiced by animal bite cases before visiting to ARV OPD. Out of total 188 cases 17 animal bite cases practiced application of lime, 40 burning of wound, 46 of them practiced burning, application of lime and veeda, 10 practiced burning of wound and application of lime, 4 burning and veeda, 1 application of lime, veeda and remaining 70 practiced none of the cultural practices before visiting to ARV OPD. ( Table 4 and Table 5) A significant difference was found between education level of animal bite cases and pre-treatment practices. $(\chi=47.119, \mathrm{P}=0.000)$. Animal bite cases with education of higher secondary and below are more likely to practice one or the other pre-treatment practices compared to those of education above higher secondary level.

\section{DISCUSSION}

Gender and residence wise distribution of animal bite cases was similar to findings in a similar study conducted by Kendre Varsharani $\mathrm{V}$ et al in same institution seven year back, that is there were more male animal bite cases as compared to female animal bite cases and majority of them were from urban area. ${ }^{13}$ Only about half of the patient ( $48.93 \%$ ) were visiting to ARV OPD within 24 hour. Similar finding were reported in study by Patil SP et $a l$ in which $47.1 \%$ were visiting to ARV OPD within 24 hour.14 The number was less as compared to study conducted by Shah venu et al and Omar Aziz Wani et al were $68.5 \%$ and $63.66 \%$ of patients were visiting to ARV OPD within 24 hour of dog bite. ${ }^{15,16}$ In present study dog were responsible for $80.31 \%$ of total animal bite cases similar to finding in a study conducted by Omair Aziz Wani et al and Nag et al in which dog were responsible for $81 \%$ and $80 \%$ of total animal bite cases respectively. ${ }^{16,17}$ In present study out of 188 animal bite cases, 88 ( $46.80 \%$ ) were of Cat III, 98 ( $52.12 \%$ ) were of Cat II and $2(1.06 \%)$ were of Cat I. Same number of Cat I patients ( $1.8 \%$ ) were found in study conducted by Nag et al, however in contrast to present study Cat III patients ( $65.8 \%$ ) were more as compared to Cat II ( 32.4 $\%$ ). ${ }^{17}$ In the present study $62.8 \%$ of total animal bite cases were practising various cultural practices before visiting to ARV OPD, similar to findings in a study conducted by Nikita Sharma et al in which $62.4 \%$ of animal bite cases were practicing various local remedies before taking treatment. ${ }^{18}$ The number is more as compared to study conducted by Omair Aziz Wani et al, Kamble B et al, Patil SP et al and Gogtay et al where $45 \%, 36.3 \%, 24.3 \%$ and $12.3 \%$ of animal bite cases were practicing various local indigenous pre-treatment practices. ${ }^{16,19,14,20}$ The percentage is somewhat less as compared to similar study conducted in similar institute by Kendre et al. in which $71.69 \%$ of animal bite cases were practicing various cultural practices before visiting to ARV OPD.${ }^{13} \mathrm{~A}$ significant difference was found between education level of animal bite cases and pretreatment practices practiced by animal bite cases in present study. Kamble B et al, in his study also found a significant difference between knowledge about rabies and education level of study population. ${ }^{19}$

\section{CONCLUSION}

More than half of animal bite cases (62.8\%) were practicing various cultural pre-treatment practices before visiting to ARV OPD. These cultural practices are of no use and many times harmful. Association between level of education and practice of various pre-treatment cultural practices was found out to be significant. It is necessary to educate people through various methods of health education measures to reduce false belief and misconception about management of animal bite and to encourage appropriate health seeking behavior among them.

\section{REFERENCES}

1. Baxter JM. One in a million or one in thousand. What is the morbidity of rabies in India? JOGH. 2012;2(1):1-4.

2. Expert consultation on rabies second report: WHO Technical Report Series 982. Geneva, 2013.

3. World Health Organization. Rabies: Fact Sheet; 2017. Available from: http://www.who.int/mediacentre/factsheets/fs099/en/.

4. 3. World Health Organization. WHO expert consultation on rabies-second report [Internet]. 2013 . Available from: http://apps.who.int/iris/bitstream/10665/ 85346/1/9789240690943_eng.pdf.

5. K Park. Park's Textbook of preventive and social medicine. Twenty Fifth Edition.Jabalpur, India: M/S Banarsidas Bhanot Publishers, 2017.p 302

6. Meneres R. Rabies in India. CMAJ 2008 February 26; 178(5): 564-66.

7. Chowdhury R, Mukherjee A, Naskar S, Lahiri SK. A study on knowledge of animal bite management and rabies immunization among interns of a government medical college in Kolkata. Int J Med Public Health 2013;3:17-20.

8. World Health Organization. Rabies in the South East Asia Region. WHO. Rabies South East Asia Regional 
Office; 2012. Available from: http://www.searo.who.int/about/administration_structure/ /CDS_RABIES.pdf.

9. Matibag GC, Ohbayashi Y, Kanda K, Yamashina H, Kumara WR, Perera IN, et al. A pilot study on the usefulness of information and education campaign materials in enhancing the knowledge, attitude and practice on rabies in rural Sri Lanka. J Infect Dev Ctries 2009;3:55-64.

10. Knobel DL, Cleaveland S, Coleman PG, Fèvre EM, Meltzer MI, Miranda ME, et al. Re-evaluating the burden of rabies in Africa and Asia. Bull World Health Organ 2005;83:360-8.

11. Singh US, Choudhary SK. Knowledge, Attitude, Behavior and Practice Study on Dog-Bites and Its Management in the Context of Prevention of Rabies in a Rural Community of Gujarat. Indian Journal of Community Medicine 2005; 30(3): 81-83.

12. Shingare AD, Gadekar RD, Doibale MK, Domple VK, Nair A, Rajput PS. Failure of post-exposure prophylaxis after dog bite. Scholars Journal of Medical Case Reports 2005; 3(9B): 877-79.

13. Kendre Varsharani V,L.T.Chinte,Y.U.Jadhav. Cultural Practices among Animal Bite Cases of Government Medical College, Latur.Medplus-International Medical Journal.2014,1(2):61-64.

14. Patil SP, Singh VS, Chavan SS et. al. Study of pretreatment practices and some of the epidemiological factors associated among dog bite cases attending outpatient department in tertiary care hospital. Int J Health Sci Res. 2014;4(4):34-39.

15. Shah venu, Bala D V, Thakker Jatin, Dalal Arohi, Shah Urvin, Chuhan Sandip et al. Epidemiological determinants of animal bite cases attending the antirabies clinic at $\mathrm{V} S \mathrm{~S}$ General Hospital, Ahmedabad.healthline 2012;3(1):2229-337.

16. Omer Aziz Wani,Gothankar J.S,Kumar Arunesh and Gupta Sachin. Profile of animal bite cases attending a Pune Municipal Corporation Dispensary. International Journal of Biomedical Research 2017; 8(02): 51-54.

17. Nag K, Karmakar N, Saha I, Paul A, Mahapatra AS, Pradhan U. Awareness and practice of animal bite management among patients attending rabies clinic of a tertiary hospital, Burdwan, India. Med J DY Patil Vidyapeeth 2018;11:521-6.

18. Sharma Nikita, Govardhan Meena, Rathore Monika, Verma Mahesh, Dilip Raj, Yadav Rajeev. A cross-sectional study of knowledge regarding rabies among attendees of anti-rabies clinic of a teaching hospital, Jaipur.JMSCR.2019,07(08):117-120.

19. Kamble B, Panesar S, Das A, Roy N, Yadav G, et al. KNOWLEDGE, ATTITUDE AND PRACTICES RELATED TO ANIMAL BITES AMONG THE RESIDENTS OF AN URBANIZED VILLAGE IN SOUTH DELHI IJRDPL.2016,5(3):2164-8.

20. Gogtay N.J.,A.Nagpal,A.Mallad,K.Patil,S.J.Stimpson, A.Belur,et al. Demographics of animal bite victims and management practices in a tertiary care institute in Mumbai, Maharashtra, India. IJMR.2019,139:459-462

Source of Support: None Declared Conflict of Interest: None Declared 